\title{
B. STEEL
}

\section{INDUSTRIAL ENERGY CONSERVATION AND THE STEEL INDUSTRY OF THE UNITED STATES}

\author{
MARC ROSS \\ Physics Department, University of Michigan, Ann Arbor, MI 48109, U.S.A.
}

\begin{abstract}
Energy use in industry, in particular manufacturing, is reviewed. Materials manufacture dominates. Natural gas and electricity are the main energy forms, with coal and oil now almost specialty fuels. Declining energy use per ton of production has characterized materials manufacture, especially since 1972. An in-depth examination of trends and future possibilities in energy use per ton of product is made for the steel industry. Energy use in 1983 is analyzed by stage of production and for the integrated and secondary sectors. Ongoing reductions in energy use by means of technical improvements are discussed for iron making, steel making and shaping-treating. A conservation plan is presented for an integrated mill, which could reduce energy use by $20 \%$ and total costs by $\$ 12$ per ton of mill product. Finally, expectations for changes in steel industry encrgy intensity in the medium term are very briefly discussed.
\end{abstract}

\section{INTRODUCTION}

The U.S. Department of Energy includes manufacturing, mining, agriculture, and construction in the industrial sector. ${ }^{1}$ Overall, industrial energy use is $38 \%$ of total energy use in the U.S. (1984). In Fig. 1 the recent history of energy consumption by industry is shown. $\dagger$ Absolute energy use declined $12 \%$ from 1973 to 1984 . The ratio of energy consumed by industry to the total constant-dollar gross national product (GNP) declined a startling $32 \%$ during the same period. In Western Europe and Japan energy prices have risen even more sharply and even more energy conservation has been carried out. Most of the costeffective conservation investments remain to be made in U.S. industries. Declining energy use per unit of economic activity is and will remain in the foreseeable future a much more important factor than increased energy supplies. For this reason it is a mistake for society to give higher priority, in education and research and in capital spending, to new sources and supplies of energy than it gives to improving the efficiency of energy use.

Industry mainly uses gas, electricity, and oil. Since 1979, gas and oil consumption have been dropping rapidly while electricity consumption has been stagnant (Fig. 2). The use of petroleum derivatives by industry is somewhat specialized; they are primarily used as fuels in petroleum refining, as feedstocks in making organic chemicals, and as motor fuels in mining, construction, and agriculture. Coal is used primarily in steel making. Coal is also, of course, a major fuel in generating electricity. Wood is an important source of energy for forest products industries. In this brief report the focus is aggregate energy use. In practice the different forms are substitutable one for the other only to a limited extent (e.g. in industrial boilers, which can burn both oil and gas), unless major investments are made.

Industrial energy use divides roughly: manufacturing $78 \%$, mining $10 \%$, agriculture $6 \%$, construction $6 \% .^{2}$ A matrix of energy use by manufacturing sector and by energy carrier is shown for 1980 in Table 1. Looking at the second from last or the last column, one sees that the basic materials sectors predominate. These sectors are (in order of energy use): chemicals, primary metals, petroleum refining, paper, and stone, clay, and glass. The energy consumption in these sectors is 81 or $77 \%$ of the manufacturing total, depending on whether electrical use is counted in terms of electrical energy or primary energy,

$†$ Notation: When customary U.S. units are used, to avoid confusion, I use $\overline{\mathbf{M}}$ to represent one million and $\mathrm{K}$ one thousand; tons (used unabbreviated) are short tons. The metric tonne is abbreviated t. Thus $1 \overline{\mathrm{MBtu}} / \mathrm{ton}=277 \mathrm{Mcal} / \mathrm{t}=1.162 \mathrm{GJ} / \mathrm{t}$. Here, as in U.S. Department of Energy practice, fuels are evaluated at their higher heating value. 


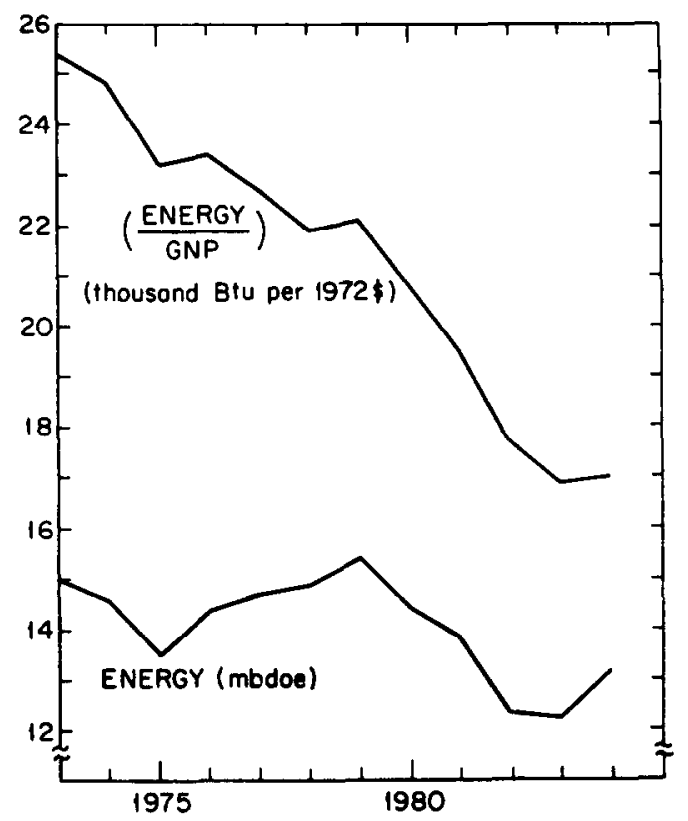

Fig. 1. Energy consumption by industry. Units: 1 mbdoe (million barrels per day oil equivalent) $=2.12$ quads $/ \mathrm{yr}=70.8 \mathrm{GW}$. 1 thousand Btu $=1.055$ MJ. Source: Ref. 1 .

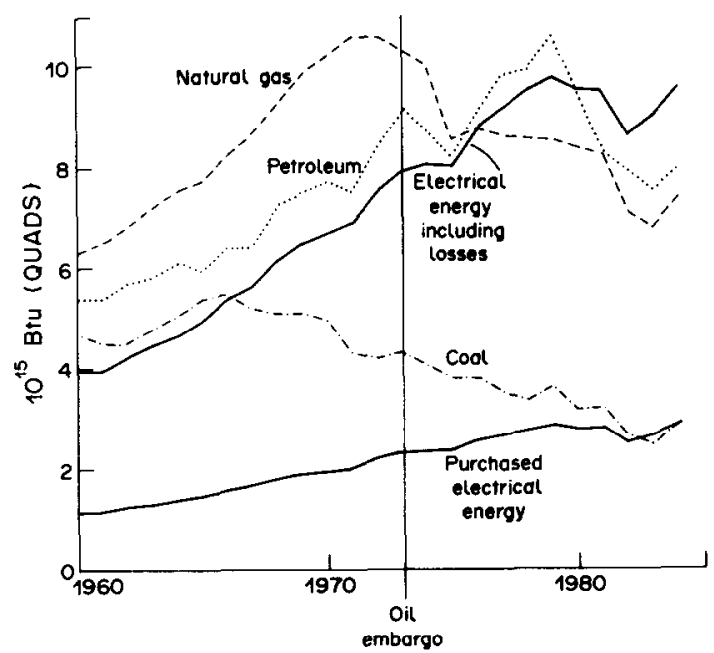

Fig. 2 . Energy use by industry. Units: 1 quad $=1.055 \times 1018$ J. Source: Ref. 4 .

respectively.

It is useful to organize the discussion of changes in industrial energy use in terms of two factors:

$$
\text { (energy use })=(\text { level of activity }) \times(\text { energy intensity })
$$

Thus energy use in steel making is the product of the tons of steel produced and the energy consumed per ton of steel. Both factors have been and will be changing. In this article I will discuss the factors that affect energy intensity and the potential for continued reductions. Detailed examples will be presented for the steel industry. Materials flows and their effects on energy will be discussed in a separate article. 


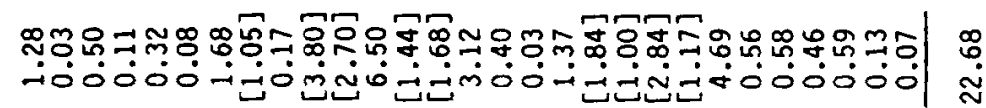

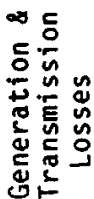

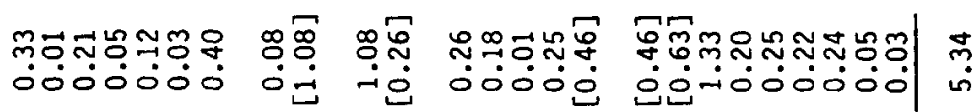

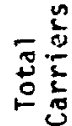

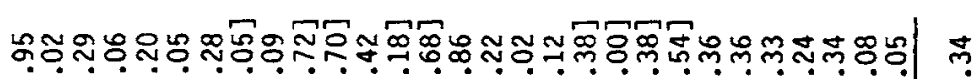

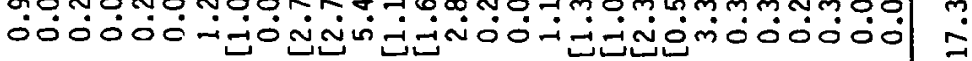

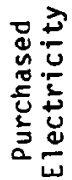

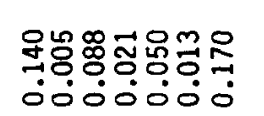

\section{制势}

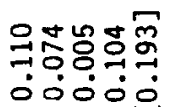

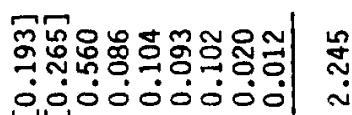

可高峦

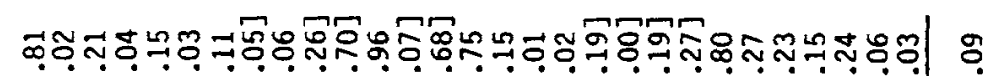

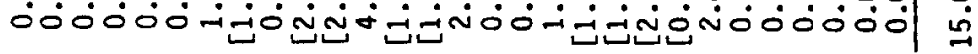

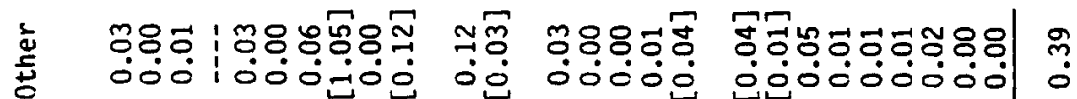

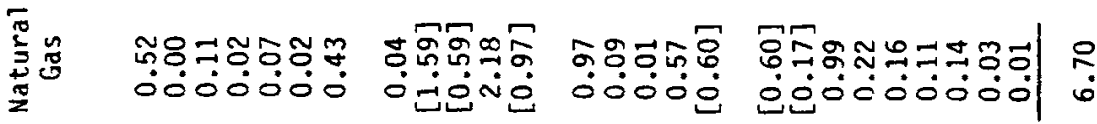

点

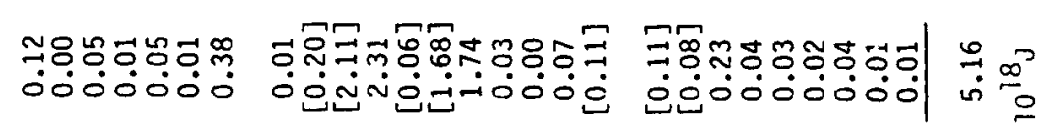

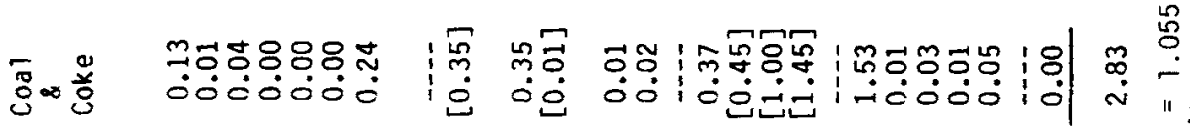
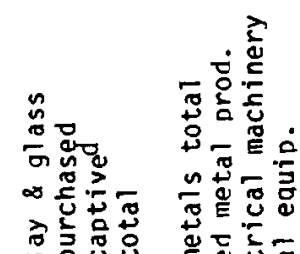

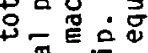

뜌웜

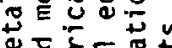

긍웡ㅇㅇ

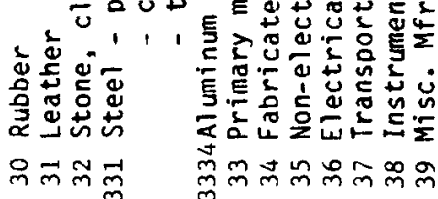

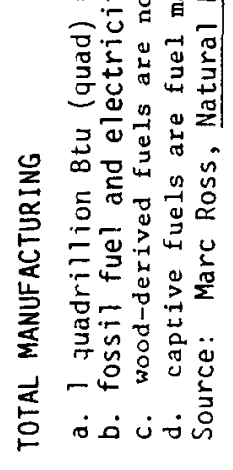




\section{THE ENERGY INTENSITY OF MANUFACTURING: DETERMINANTS OF ENERGY INTENSITY}

The energy intensities for certain basic materials are shown in Table 2. This is the energy used within each manufacturing sector to produce an average ton of product. The theoretical minimum energy, or thermodynamic availability, to manufacture each material

Table 2. Energy intensities for selected basic materials

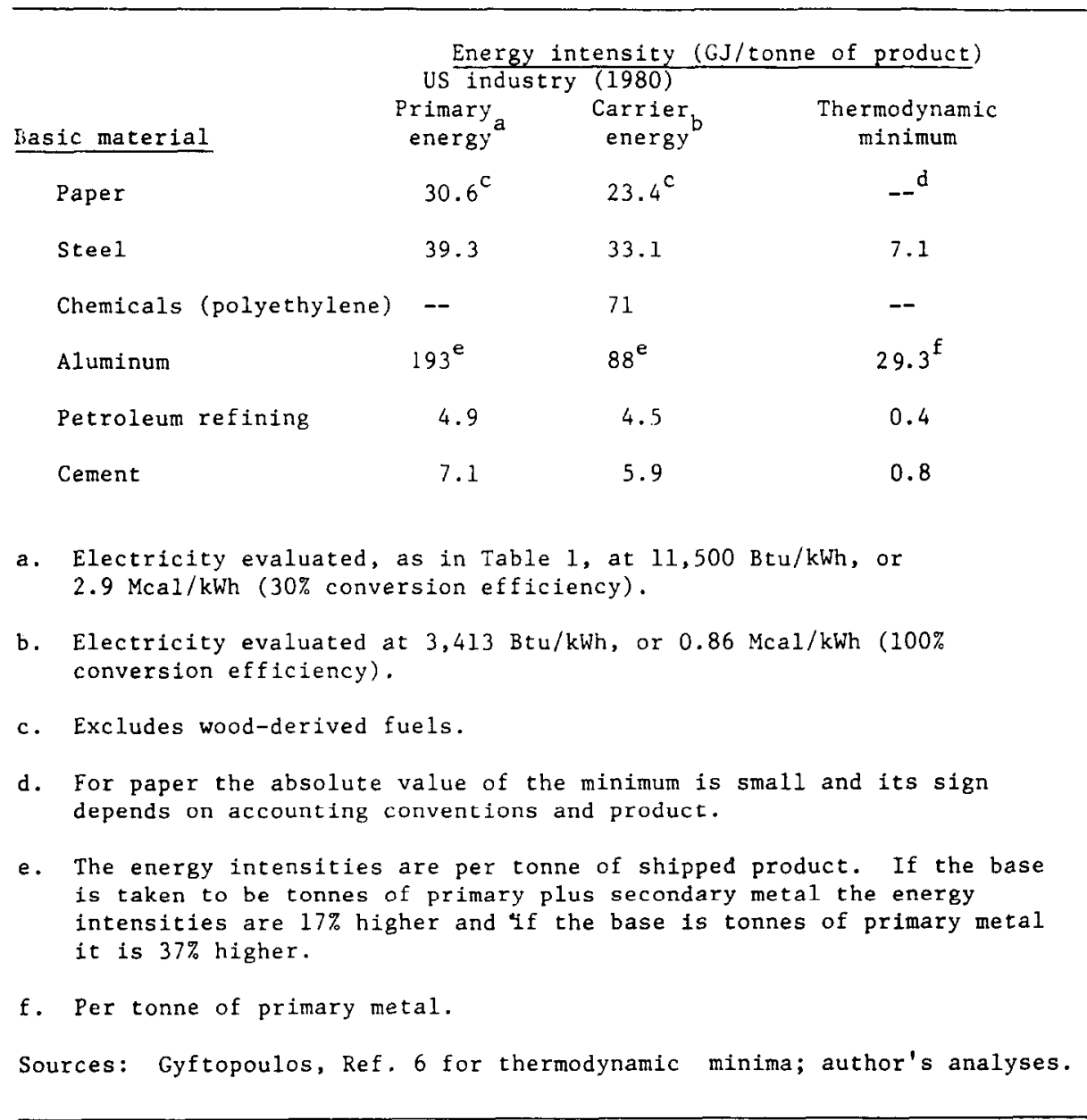

is also shown in Table 2. Only in the cases of reduction of metal ore are the availability requirements really large. $\dagger$ Some other chemical rearrangements, such as in petrochemical manufacture, also have significant availability requirements. Physical rearrangement, separation of components in wood to make paper, the shaping of metals, and the assembly of parts, requires very little energy ideally. Typically those process stages with large availability requirements, for example reducing iron in a blast furnace or reducing alumina using the Hall process, are carried out fairly efficiently in average practice. (Carrier energy use is roughly $50 \%$ efficient in these two cases.) Because so much energy is involved, it nevertheless pays to continue striving to make the process more energy efficient. Most process stages in industry do not, however, have substantial availability requirements and are, in this ideal sense, astonishingly energy inefficient. In these cases huge relative energy savings are, in principle, possible and in some cases are being achieved.

The energy used to produce a unit of a given material has been declining. This decline has accelerated since 1972 (Table 3). The average rate of decline since 1972 has been $2 \% / y r$, largely driven by increasing prices for energy (Fig. 3). Energy prices paid by industrial customers tripled relative to the average prices of other purchases 1973-1982. Compared 
Table 3. Reduction of energy intensitya in the basic materials industries (1972-1983)

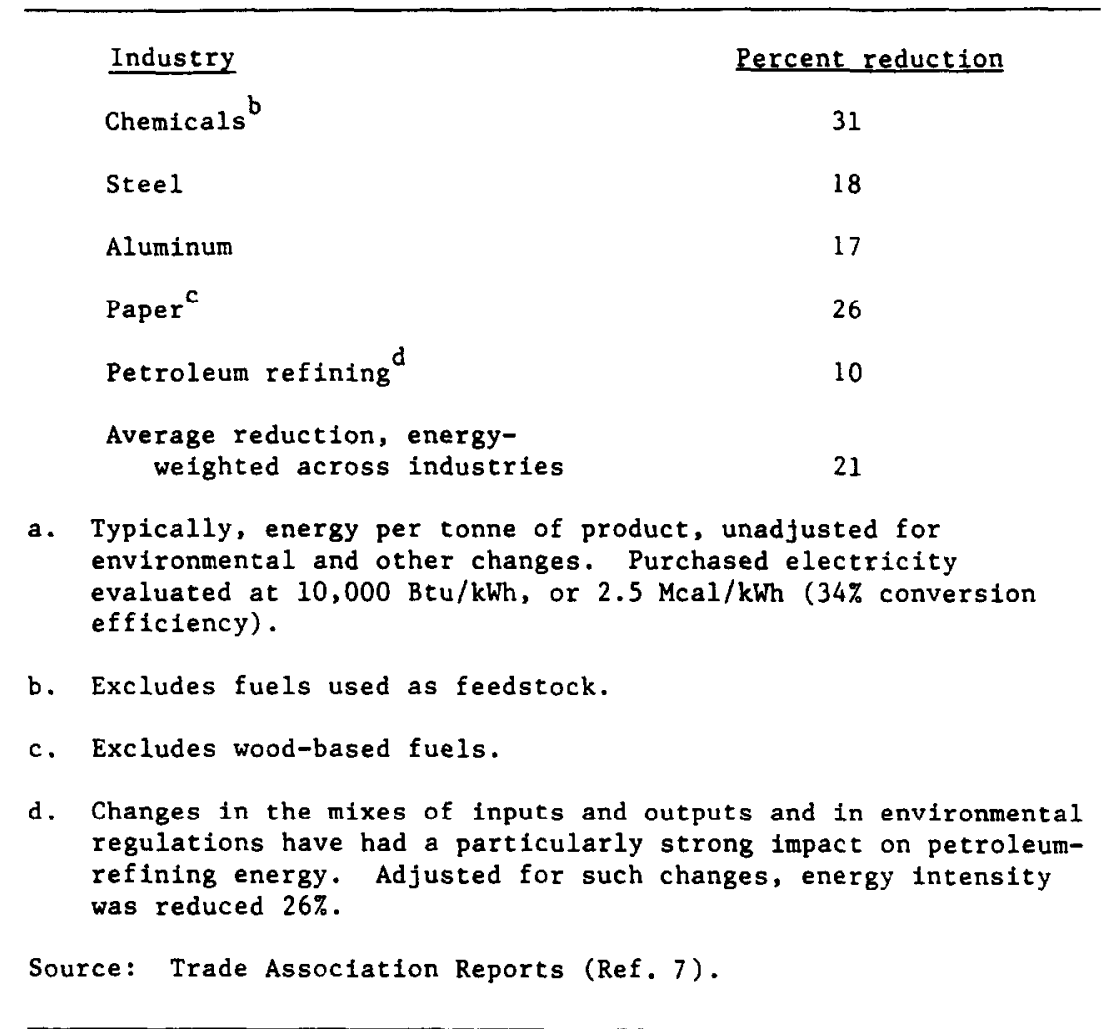

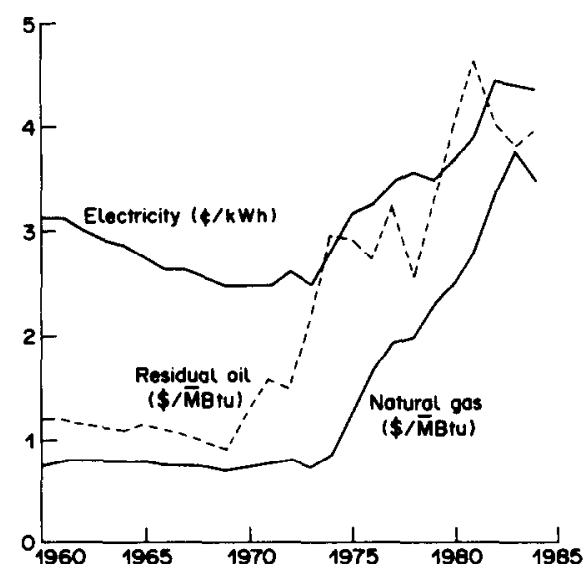

Fig. 3. Price of energy to industrial users (national average, 1980\$). Units: For residual oil $\$ 1.00 / \overline{\mathrm{M}}$ Btu corresponds to $\$ 0.15 /$. For natural gas $\$ 1.00 / \overline{\mathrm{M}} \mathrm{B}$ tu corresponds to $\$ 35 / \mathrm{km} 3$. Prices were deflated using the Producer Price Index for all commodities. Source: Ref. 4.

to industrial value added - the cost of labor, management, and capital - the average cost of energy to industry has risen from $5 \%$ in the late 60 s and early 70 s to over $10 \%$.

The cost of energy to value-added ratio varies widely across sectors. While manufacturing exclusive of basic materials has a ratio of only $3 \%$, several major basic materials subsectors (pulp and paper mills, basic chemicals, petroleum refining, cement, basic steel, and primary aluminum) have ratios of $1: 4,1: 3$, or more. ${ }^{3}$ Within the basic-materials sectors, upstream activities tend to be more energy intensive and downstream activities more value-added or labor-intensive.

It should not be assumed that the cost of energy is the only important motivation for industrialists to increase energy efficiency. The threat of energy shortages is an important 
motivation as is the societal goal to reduce the dependence on imported oil. In addition, there is a pattern to major innovations in manufacturing processes: they tend to create savings in all factors of production: labor, capital, materials, and energy.

\section{REDUCING THE ENERGY INTENSITY OF STEEL MANUFACTURE}

\section{A. Manufacturing Process and Energy Use}

Total materials flows in the various stages of steel making in the U.S.A. are shown in Fig. 4. An integrated steel mill involves three major process stages: iron making, steel making, and shaping and treating. The key processing facility in iron making is the blast furnace, a vertical shaft where iron-oxide agglomerates are placed with coke and flux, and hot air injected near the bottom. The high temperature (about $1500^{\circ} \mathrm{C}$ ) and strongly reducing atmosphere (carbon monoxide) produces molten iron with approx. $4 \%$ dissolved carbon, and some silicon, manganese, sulfur, and trace materials. The gangue from the ore and the coal ash collects in a slag. The blast furnace requires coke (made from metallurgical coal) and sinter (an agglomerate made at the mill) or pellets (an agglomeratc typically made near the mine).

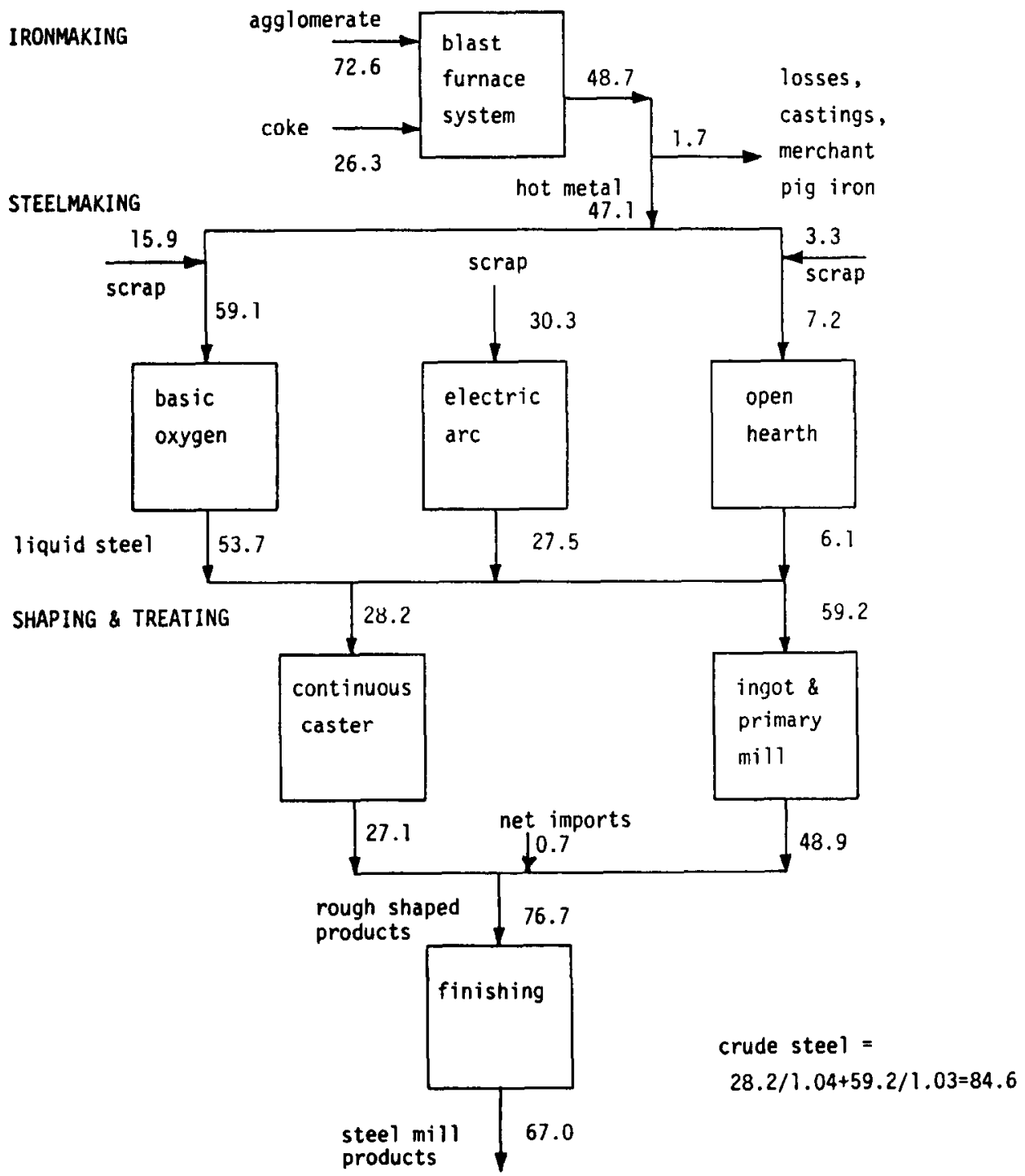

Fig. 4. Major material flows, steel mills in the U.S. (million short tons, 1983). 
Steel making in its narrow sense involves creation of molten iron with controlled quantities of additives such as carbon. In the basic oxygen facility, oxygen is blown into the molten high-carbon metal, removing carbon down to a desired level of $0.1-1.0 \%$. Removal of such impurities as sulfur, oxygen, phosphorus and hydrogen down to very low levels is done in separate steps, as is alloying. About one quarter of the iron input is scrap from sources internal or external to the mill, which acts as a coolant. In the electric arc steel-making scrap is melted, and impurities removed and alloying elements added.

Shaping involves either casting the liquid steel directly into a desired rough shape (continuous casting), or into large ingots, which are then evenly heated in soaking pits and rolled into rough shapes in a primary mill. The product at the ingot or continuous casting stage is called raw or crude steel, that at the primary mill or continuous cast stage is semifinished or rough shaped. In the finishing stage the rough shapes are reheated and rolled into flat shapes such as thin sheet or into product shapes such as bars, or drawn into pipe or wire. Many hot rolled products are also then cold rolled. Many of these products are also heat treated (annealing) and/or surface treated in a variety of ways. The mill products are shipped to fabricators (typically considered to be outside the industry) who shape them further in producing consumer products.

There is a separate secondary steel industry in the U.S., which makes steel by melting scrap in electric furnaces. There are two sectors based on this process: a relatively small specialty steel sector (based on special scrap) and the so-called minimills, which make a limited range of relatively simple products from low-priced scrap. About $18 \%$ of steel mill products are made by minimills, an increasing share. Comparable production by electricarc furnaces occurs at minimills and integrated mills.

\section{Energy use}

The steel industry's predominant fuel is coal as shown in Table 4; a great deal of natural gas and electricity is also consumed. The coal is primarily of metallurgical quality, used to make coke for blast furnaces. The by-product fuels of the coke oven and blast furnace are used throughout the mill. Electricity is primarily used to operate rolling mills and electric arc furnaces.

Table 4. Steel industry energy use by fuel (1983)

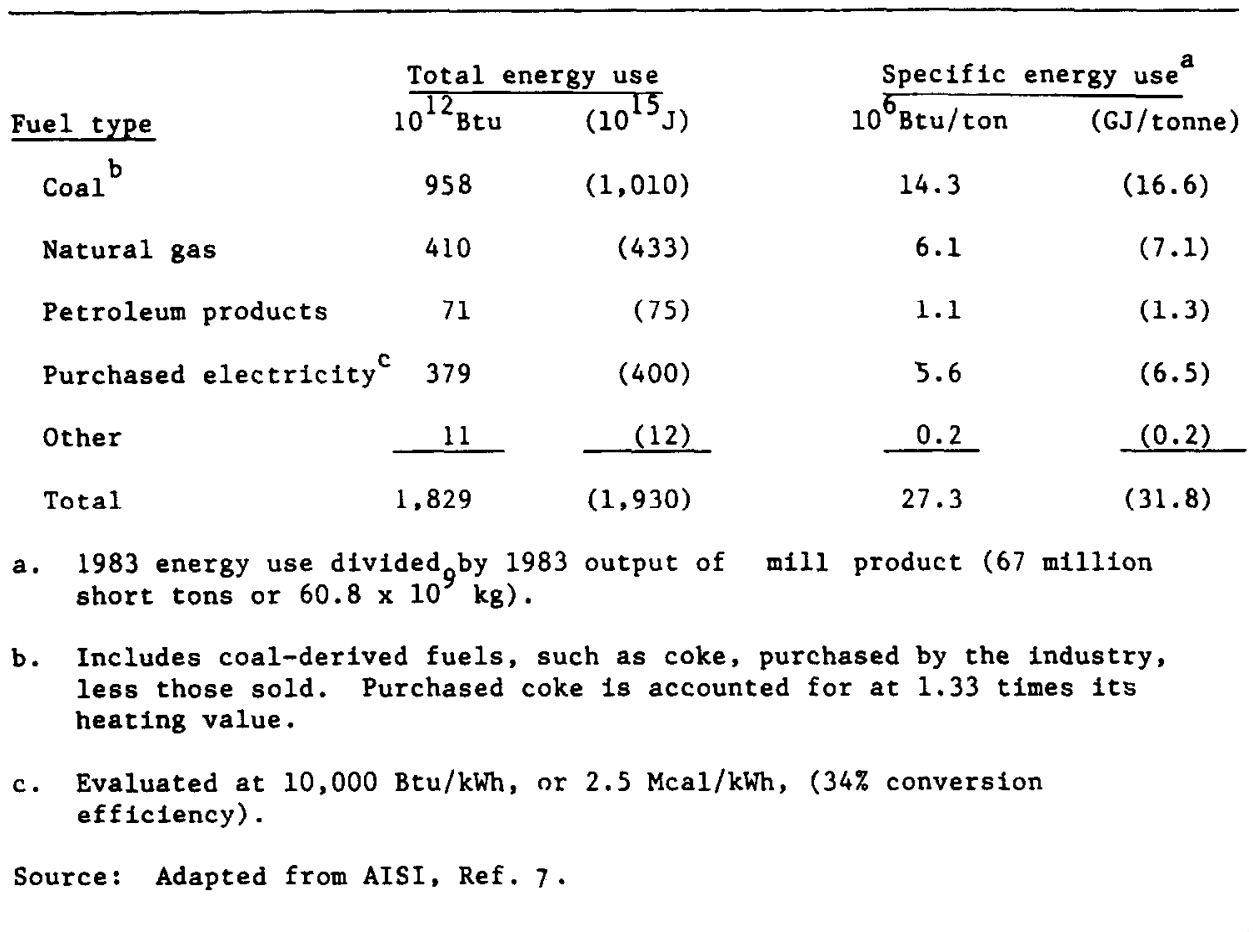




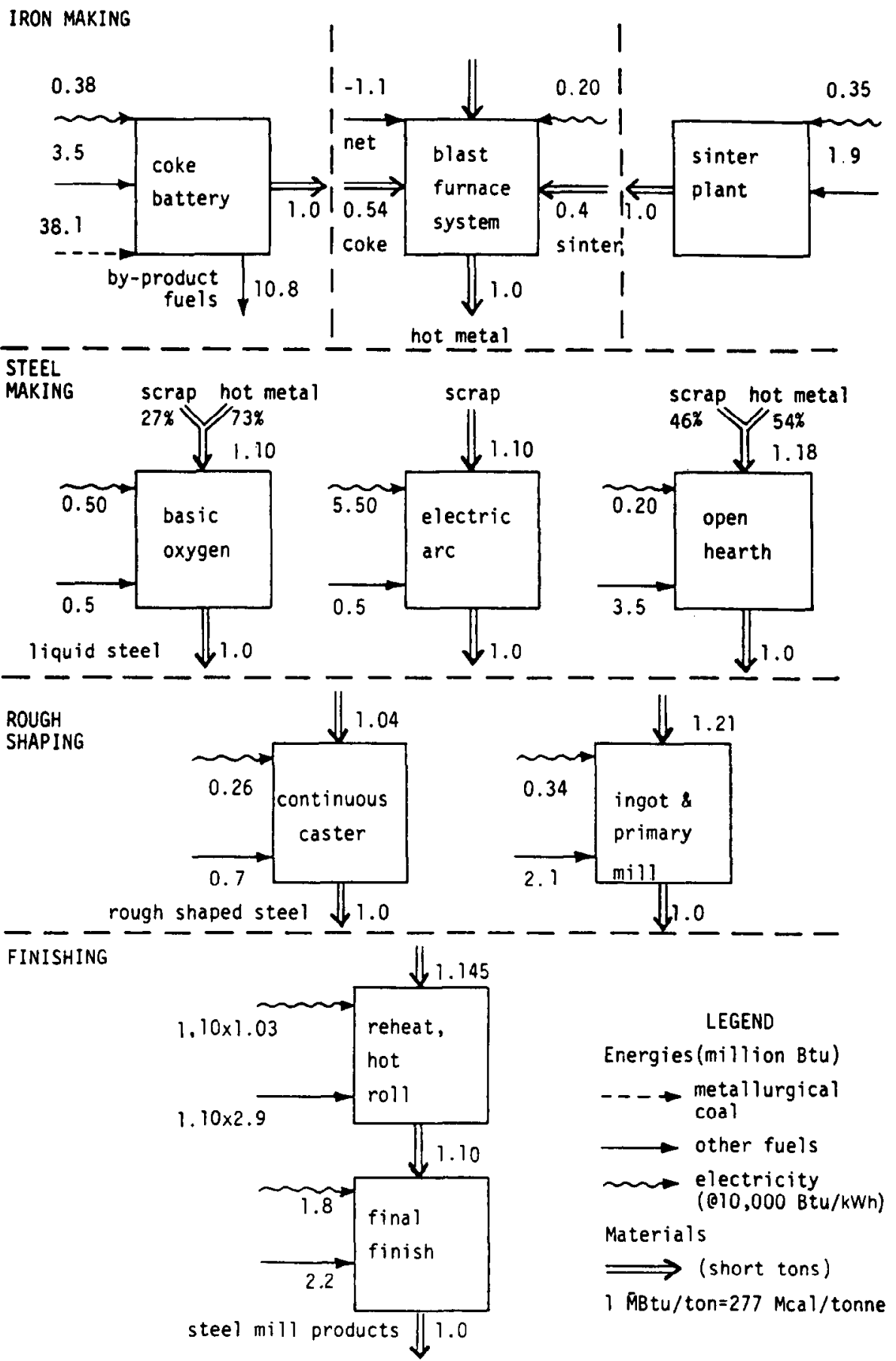

Fig. 5. Energy use and yields per unit of stage production, 1983.

Energy use by process stage is shown per unit of stage production in Fig. 5; and per ton of mill product in Table 5. About half the energy is used in the iron making stage. In the thermodynamic ideal only iron making requires substantial energy consumption. Energy use in the other process steps could, in principle, be reduced to negligible values. This is reflected in extraordinary reductions in energy use in steel making and shaping achieved at some mills.

Integrated mills use about twice as much energy per ton of product as secondary mills in average practice, as shown in Table 6. Integrated mills consume about $15 \overline{\mathrm{MBtu}}$ /ton of 
Table 5. Energy use by process stage, industry average (1983). (M̄Btu/ton of mill product. Multiply by 277 to obtain Mcal/t)

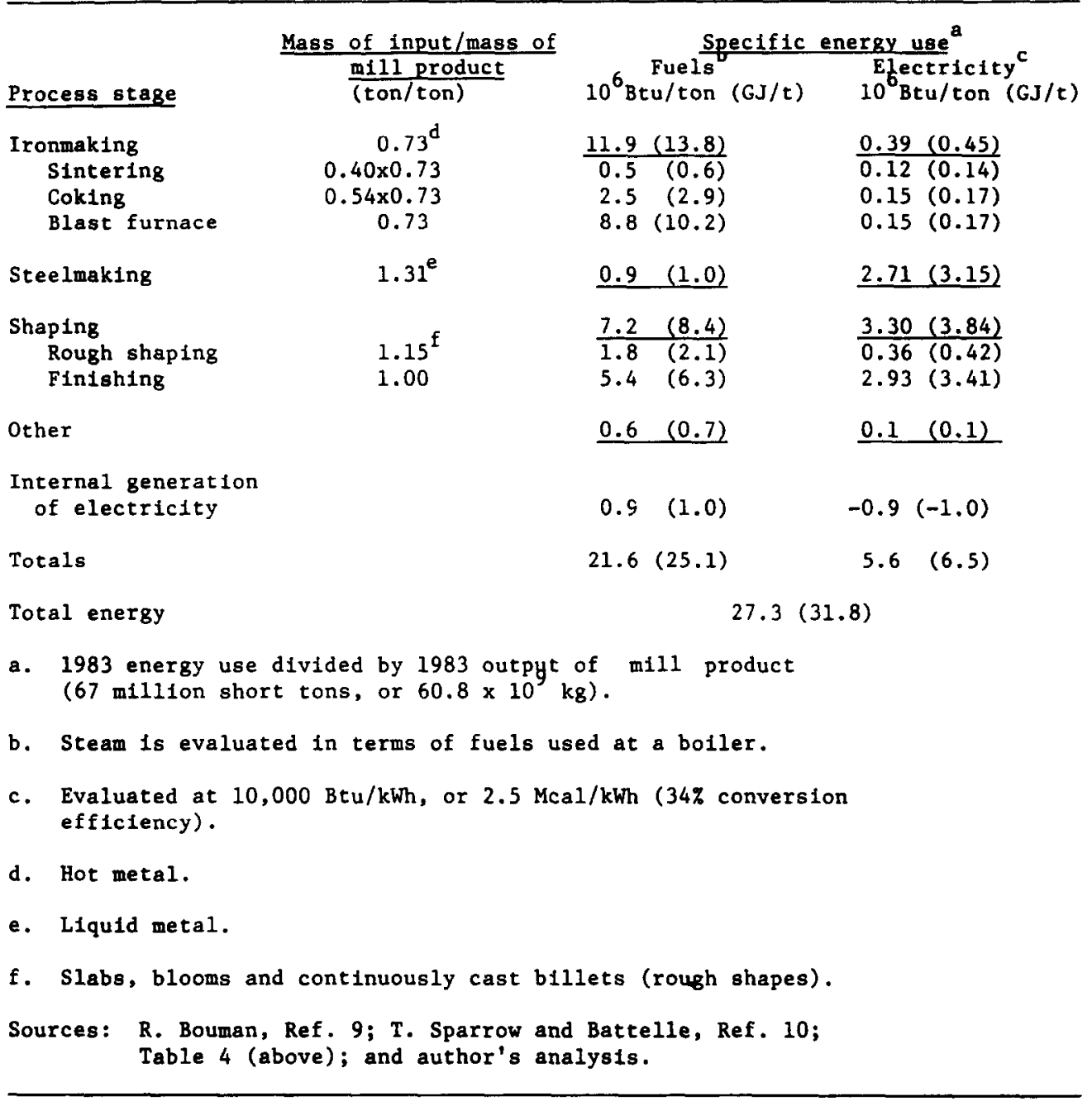

mill products $(4.1 \mathrm{Gcal} / \mathrm{t})$ in iron making alone. Secondary mills enjoy the great energy advantage of the embodied energy in steel scrap. On the other hand, secondary mills use close to $7 \overline{\mathrm{MBtu}} /$ ton of mill product $(2.0 \mathrm{Gcal} / \mathrm{t})$ to melt the scrap. The mix of products also gives the minimills an energy advantage. The impurities in post-consumer scrap and the minimill's business strategy of concentrating on products with low unit capital and labor requirements have limited the types of products typically made in those mills to bars (such as reinforcing bars for concrete), simple structural sections, and wire rod (from which wire is drawn). As a result less energy per ton of product is used in shaping and treating than in integrated mills.

From 1972 to 1983 aggregate energy use by the steel industry dropped about $44 \%$. Most of this decline is due to the decline in production. During this period the energy intensity of steel manufacture declined $18 \%$, at an average rate of $1.8 \% / \mathrm{yr}$ (Table 3 ).

\section{B. Energy Intensity and Technical Change}

The kinds of technical change that lead to improved efficiency of energy use can be roughly categorized: (1)Changes in operations and maintenance, and retrofits with low cost equipment, which lower energy use. (2) Changes in the major processes of production. Often major process changes require a new facility costing $\$ 100$ million or more, but not 
Table 6. Average energy use by type of steel mill (1983) ( $\overline{\mathrm{M} B t u}$ /ton of mill product. Multiply by 277 to obtain $\mathrm{Mcal} / \mathrm{t}$ )

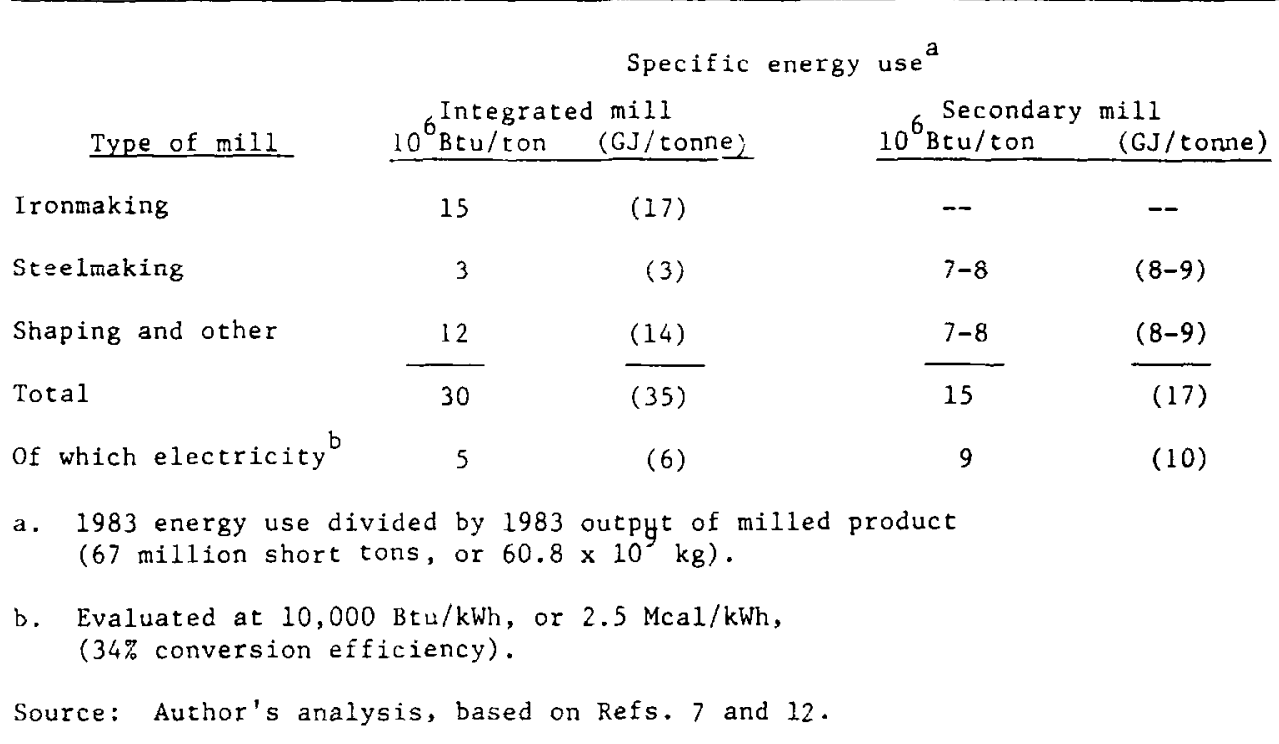

necessarily. (3) Changes in energy-intensive equipment or energy conservation add-on technologies, which involve significant investment (typically $\$ 50,000$ to a few tens of million dollars) and are largely justified by reduced energy costs.

\section{Improved operations}

This is, in part, what is called housekeeping. In order to make good progress a wellqualified staff is needed to carry out energy conservation activities, with top management leadership and support. Among general practices and technical changes are: management practices such as inspections to encourage conservation activity; training programs for operation of energy-intensive equipment; scheduling of energy-intensive activities; turning off motors when not in use; turning down heaters as appropriate; systematic maintenance programs; accounting procedures to charge energy costs to production departments (not to general overheads); and low-level investment programs such as direct metering of major energy-using facilities and sophisticated inspection equipment such as infrared scanners.

One way to improve operations that has proved successful at some mills is employee participation in energy conservation, including systematic solicitation of employee suggestions for technical changes (e.g. using quality circles).

\section{The potential for radical process change}

Two major process changes now being widely adopted throughout the world are the elimination of open-hearth furnaces in favor of basic-oxygen and electric-arc steel making, and the substitution of continuous casting for the ingot route. The energy implications of these changes will be discussed briefly in a later section. Although the emphasis of this report is improvement of existing plants, it is important to consider also the potential for new process technologies. Among radical changes now the subject of research and development, one that might become available and be widely adopted during the next decade is the extension of continuous casting to cast shapes much nearer in thickness to final products, e.g. 1-inch $(25 \mathrm{~mm})$ slabs. ${ }^{13}$ Associated with this would be more direct rolling (i.e. rolling the casting while still hot) and automation of the later stages of treatment.

Another focus for development is iron and steel making. Efforts include reduction of iron oxides with plasmas, reduction directly with coal rather than coke, and continuous steel making. ${ }^{14,15}$ These approaches have the potential to save energy, but above all are aimed at reducing unit capital costs (perhaps also justifying smaller-scale plants) and at 
use of a less expensive fuel/reductant such as ordinary coal. One approach to lower capital costs is to try to create steel from oxides in a single facility (in place of the present four: agglomeration plant, coke ovens, blast furnace, and steel shop).

A development which might involve but little technical effort would be processes to remove (or reduce the effects of) deleterious materials, especially copper, ${ }^{16}$ in post-consumer scrap. Possible steps range from redesign of products like cars to make separation easier, improved separation techniques by scrappers, sophisticated separations from the meit at the steel mill, and shaping and treating techniques to reduce, e.g., the embrittlement normally caused by copper. (The last-mentioned possibility has radical potential because thin casting technologies under development should enable very rapid solidification and, thus, the achievement of new internal structures.) Since the U.S. produces a lot of postconsumer scrap and has large reserves of old scrap, any development extending the use of that scrap to more demanding kinds of products would improve the competitive position of U.S. producers.

\section{Current technologies for reducing energy intensity}

In this section various kinds of technical changes to reduce the energy intensity of steel making will be presented by stage of processing. Many changes are not primarily aimed at energy conservation but are very effective in conserving energy. Yield improvements are a prime example.

Ironmaking. Two processes are in wide use in the world, the blast-furnace process producing molten iron, and direct reduction producing a sponge-like iron. Direct reduction has not been significant in the U.S. One reason for lack of interest at present is the high cost of natural gas, which, although other fuels can be used, is the fuel of choice. Direct reduction has been particularly successful at geographical locations where natural gas is cheap. I will not mention it further.

I include in the iron-making stage the blast furnace, coke ovens, and sinter plant. At the blast furnace itself current average U.S. practice involves net use of $12.3 \overline{\mathrm{MBtu}}$ of fuel per ton of hot metal $(3.4 \mathrm{Gcal} / \mathrm{t})$; in very good practice $10.9 \overline{\mathrm{MBtu}}$ is used, ${ }^{11}$ while ideal thermodynamics requires $7.7 \overline{\mathrm{MBtu}}$ per ton of hot metal $(2.1 \mathrm{Gcal} / \mathrm{t}){ }^{6}{ }^{6}$ The conclusion is clear: while average practice provides a substantial opportunity to reduce energy intensity, in percentage terms that opportunity is limited.

Of the opportunities to reduce blast-furnace energy intensity, I will briefly discuss changes in the burden (especially agglomeration of concentrated iron oxides), improved spatial distribution of the burden, and injection of fuel. Over the decades improvements in blast-furnace operations and the closure of antiquated furnaces have led to a steady decline in the coke rate, the ratio of consumption of coke to molten metal produced (Fig. 6). The average rate of decline is 0.74 points $/ \mathrm{yr}(7.4 \mathrm{~kg}$ coke per tonne of hot metal, per year). We are in effect discussing the means by which this decline in energy intensity can be continued.

One of the outstanding postwar successes of the steel industry in North America was the shift from ore to agglomerate. It was thought that the declining concentration of iron in ores spelled serious difficulties for the industry. Instead, beneficiation and agglomeration of ores into pellets reduced overall costs and energy use, in part because the pellets mean a more uniform burden of higher iron concentration in the blast furnace. Today almost no ore is used as lumps in blast furnaces. Further improvements can be achieved by screening pellets so that small pieces and dust (fines) can be diverted and reagglomerated at the sinter plant. Similarly, systematic procedures to create a more uniform and higher quality coke are meeting with success in spite of occasional difficulties with coal quality.

Control over the distribution of the burden in the furnace can be improved by loading the furnace through a top that incorporates a controlled chute (rotating about a vertical axis and swinging out to determine the radius at which material is dropped). The Paul Wurth bell-less top was first applied in 1972 in Germany and in the U.S. and U.S.S.R. in 1978. The capability to control distribution of materials in detail can yield advantages including increased production, reduced coke rate, reduced damage to furnace lining, better 


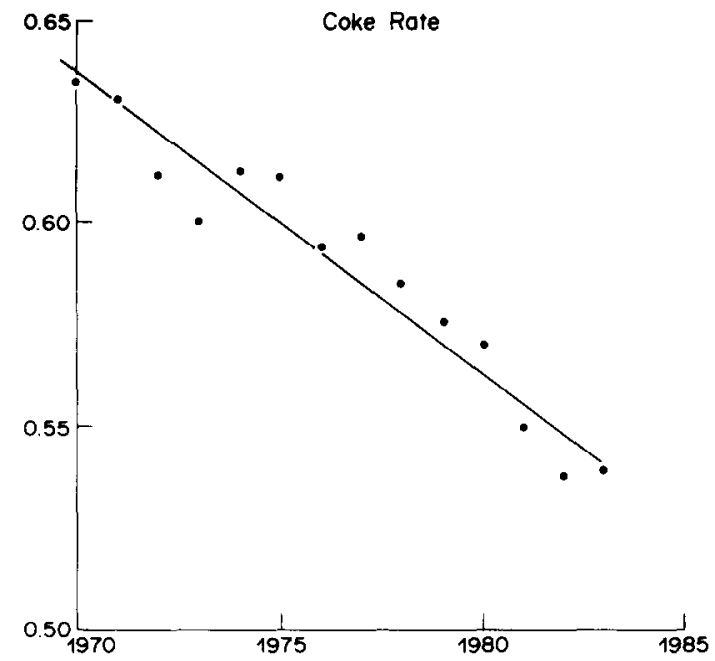

Fig. 6. Coke rate. Source: AISI Statistics, Ref. 8.

control of temperature and chemistry, and reduced maintenance. In a retrofit application a new top on a moderate size furnace is estimated to cost about $\$ 20$ million and to reduce coke requirements by about $6 \%$.

An innovation receiving considerable attention is injection of pulverized coal at the tuyeres of the blast furnace. ${ }^{17,18}$ With fuel injection, energy use at the blast furnace increases, but is more than compensated for by the implications of decreased use of coke. Since 1979, with higher oil and gas prices, the use of oil and gas injectants per ton of production has sharply declined in the U.S. Coal injection has more promise. A proposed coal-injection facility for a large blast furnace is estimated to cost about $\$ 20$ million. (A coal-water slurry, if feasible, could be substituted for oil injection at much lower cost.) Injection of $220 \mathrm{lbs}(100 \mathrm{~kg})$ of coal per ton of hot metal is calculated to provide overall energy savings of $1.1 \overline{\mathrm{M}} \mathrm{Btu} / \mathrm{ton}$ of hot metal $(0.3 \mathrm{Gcal} / \mathrm{t}){ }^{1{ }^{11}}$ (Incrcased purchases of electricity are valued at $10,000 \mathrm{Btu} / \mathrm{kWh}$ or $2.5 \mathrm{Mcal} / \mathrm{kWh}$.)

Many other improvements are being implemented: increased blast temperatures, recovery of power via expansion turbines from the gas exiting the furnace (if at high enough pressure), ${ }^{19}$ external desulfurization (or removal of sulfur from hot metal in the ladle rather than in the blast furnace, permitting less costly operation of the furnace), and a number of relatively conventional conservation actions for blast-furnace stoves. I will not discuss them.

Clearly, changes at the blast furnace interact with coke making and agglomeration. There are also energy-conservation opportunities specific to those facilities. I will discuss coke making only. The widely discussed potential for recovery of sensible heat (e.g. dry coke quenching) is not being acted on in the U.S.; there is also little preheating of coal. One of the major changes in the U.S. is the rebuilding of aged coke ovens and the building of new ones, primarily to meet tighter pollution regulations. Another ongoing change is increased capability for underfiring of coke ovens with blast-furnace gas to broaden the opportunities for use of that by-product fuel. An impending development is advanced controls for the scheduling, degree and distribution of heating and timing of extraction of the coke.

Steel making. In converting the high-carbon molten metal from a blast furnace to steel, the oxidation of carbon, silicon, and manganese is exothermic, which results not only in no need for heat input but also in the possibility to melt scrap (up to over $25 \%$ of the metal) in basic oxygen steel making. The low use of energy ascribed to steel making (narrow sense) from the molten blast-furnace product is partly the result of the customary energy accounting convention where neither the sensible heat of the hot metal nor the carbon and other reduced materials dissolved in it, nor energy use in oxygen production 
is counted as an energy input to this stage. Energy use can be reduced further by capture of the $\mathrm{CO}$, which is given off in basic-oxygen steel making. This conservation technology is in wide use in Japan and is being considered in the U.S. At one large steel mill the capital cost for facilities to capture and handle basic oxygen off gas is estimated to be about $\$ 50$ million. The energy saving is about $0.66 \overline{\mathrm{MBtu}} /$ ton of liquid steel $(0.18 \mathrm{Gcal} / \mathrm{t})$. The fuel value of the gas is about $240 \mathrm{Btu} / \mathrm{scf}\left(2.1 \mathrm{Mcal} / \mathrm{m}^{3}\right){ }^{11}$

Most basic oxygen vessels involve a lance to blow in oxygen from the top. But the technology is now in flux. Injection of gas from the bottom in addition has been widely adopted. For example, introduction of an inert gas (such as argon) at the bottom for stirring improves the chemistry and yield, and, in some operations permits a higher ratio of scrap in the charge. ${ }^{20}$ In one analysis, if the scrap charge is increased from 25 to $29 \%$, total mill energy consumption decreases by $2.4 \%{ }^{11}$ There might be strong secondary effects nationally of a significant increase in scrap handling capability in the BOP, through an increase in the price of scrap. ${ }^{21}$ Since a brief shortage in the U.S. in the early 1970s, scrap prices have been low and exports high; and scrap supplies have not been fully exploited.

Increased prices would affect the competitiveness of the minimill industry. A major development in U.S. steel making has been the rapid displacement of the inefficient openhearth furnace by basic-oxygen and electric-arc furnaces with substantial energy savings. In 1983 only $7 \%$ of steel was produced in open hearths in the U.S. In Japan and Sweden open hearths are no longer used.

The electric-arc furnace is presently the technology of choice for melting and refining charges of $100 \%$ scrap steel. Melting involves the transfer of $1.1 \overline{M B t u}$ to each ton of scrap $(0.3 \mathrm{Gcal} / \mathrm{t})$. With ideal thermodynamic techniques (i.e. with a perfect heat pump) this could be accomplished with as little as $0.7 \overline{\mathrm{M}} \mathrm{Btu}$ of fuel energy $(0.19 \mathrm{Gcal} / \mathrm{t})$. With an electric-arc furnace in average practice about $2.4 \overline{\mathrm{M}} \mathrm{Btu}$ (including the carbon electrodes and ancillary services) is consumed per ton of liquid steel $(0.66 \mathrm{Gcal} / \mathrm{t})$, or $6 \overline{\mathrm{MBtu}}(1.7 \mathrm{Gcal} / \mathrm{t})$ counting fuel use at the power plant.

Just as there are a wide variety of improvements now being made in basic oxygen, there are in electric-arc steel making. ${ }^{22}$ Among these are recovery of heat from off-gases with its use to preheat scrap. (Other sources of waste for preheating scrap are also being used.) Other technologies run from much higher power levels, automatic controls for the voltage and power factor, and for the position of the electrodes, coatings to reduce electrode loss, to water cooling of the sides and insulation. A direct current arc with substantial savings in electrode loss is being tried. I will not discuss these.

Another important development in steel making in its narrow sense is ladle chemistry. More of the refining of hot metal and liquid steel is being conducted in separate steps in ladles. The benefits are greater control of the chemistry and reduction of constraints on steel-making furnace and blast-furnace operations so they can be optimized for their principal functions. By these means it is becoming possible to remove inclusions and make clean steel. Energy conserving techniques for heating, drying, and insulating ladles are being widely implemented.

Shaping and treating: rough shaping or semifinishing. The most prominent change in shaping technology is continuous casting. In 1983 the fraction of steel continuously cast in the U.S. rose to $32 \%$. The fraction in some other countries is much higher, e.g. $86 \%$ in Japan. Continuous casting offers important benefits in product quality for most products because of its uniformity and reduction of defects in solidification. (In the U.S. the ingot route is preferred for a few products.) Ultimately the main benefit of continuous casting and direct rolling may be the rapid feedback, which could eventually enable the elimination of most errors in production, which now result in substantial rejection of finished and semifinished products.

Continuous casting is probably the largest single contributor to the substantial yield improvements of the past dozen years (Fig. 7). The dashed line in Fig. 7 is an estimate of the yield increase due to continuous casting starting with the base period 1975-1976. A substantial yield increase has also been achieved in primary mills and in the rest of the 


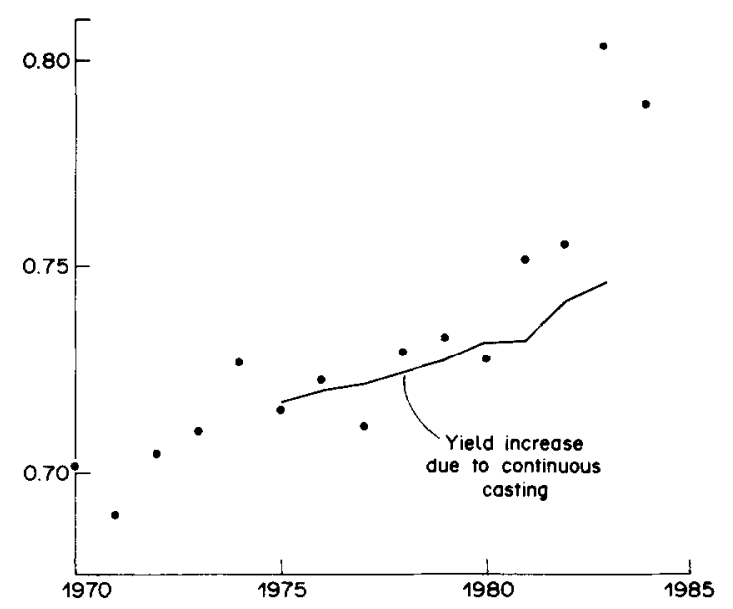

Fig. 7. Yield: The ratio of mill product to crude steel. Source: AISI, Ref. 8. Inventory corrections from Ref. 27.

finishing process. A significant part of the very recent increase is due to net imports of ingots and rough shapes.

Continuous casting has large immediate energy benefits. The direct savings are about $1.6 \overline{\mathrm{MBtu}} /$ ton of rough shaped steel $(0.4 \mathrm{Gcal} / \mathrm{t})$. In addition, about 0.17 ton more liquid steel per ton of rough-shaped steel is presently required with the ingot route than for continuous casting. The improved yield of continuous casting results in savings of more than $2 \overline{\mathrm{MBtu}} /$ ton of rough-shaped steel $(0.6 \mathrm{Gcal} / \mathrm{t})$. The savings from these two sources approach $4.5 \overline{\mathrm{MBtu}} /$ ton of mill product $(1.2 \mathrm{Gcal} / \mathrm{t})$, with average U.S. practices. The capital cost of a continuous casting facility is roughly $\$ 100$ million for a slab caster with capacity of $1 \overline{\mathrm{M}}$ ton/yr.

The ingot route is also being improved. In very good practice, the ingot-soaking pitprimary rolling process only requires 0.064 ton more liquid steel than continuous casting to produce a ton of rough-shaped steel. ${ }^{11}$ In addition, fuel use at the soaking pit can be drastically reduced. In the pre- 1973 climate, these heaters were designed in a manner which is extraordinarily wasteful from our present perspective. Where in present practice soaking pits use $1-2 \overline{\mathrm{MBtu}} / \mathrm{ton}$ of rough-shaped steel $(0.3-0.6 \mathrm{Gcal} / \mathrm{t})$, very good practice only requires $0.35 \overline{\mathrm{MBtu}} /$ ton $(0.10 \mathrm{Gcal} / \mathrm{t}) .{ }^{11}$ Many factors contribute to this improvement, the most important probably being charging ingots into the soaking pit quickly (where appropriate). Improvements in the soaking pit proper, most of which are being adopted in the U.S. because of their extremely short payback, include a supervisory computer ${ }^{23}$ to control timing and distribution of heating, automatic combustion controls, increased recovery of heat from stack gases to preheat fuel gas and combustion air, and extensive insulation of pits. In one example based on part of these opportunities, energy use was reduced from $1.1 \overline{\mathrm{MBtu}} / \mathrm{ton}(0.3 \mathrm{Gcal} / \mathrm{t})$ to below $0.4 \overline{\mathrm{MBtu}} / \mathrm{ton}(0.1 \mathrm{Gcal} / \mathrm{t}){ }^{24}$

$H o t$ rolling. As with soaking pits, extraordinary energy savings are available in reheat furnaces. ${ }^{25}$ In current practice, almost $3 \overline{\mathrm{MBtu}} /$ ton of hot-rolled product $(0.8 \mathrm{Gcal} / \mathrm{t})$ is used for reheating. In very good practice this is reduced to about $1.0 \overline{\mathrm{M}} \mathrm{Btu} / \mathrm{ton}(0.3 \mathrm{Gcal} / \mathrm{t})$.

A significant reduction in energy use is possible through hot charging. The potential to put hot steel slabs (let us say) into a reheat furnace for rolling depends on factors like the location of the separate mills, the possibilities for insulating the slabs in transit to the furnace, the quality of the slabs, and the discipline of the staff. In one estimate, $20 \%$ hot charging of slabs at $1100^{\circ} \mathrm{F}$ results in a reduction of $7 \%$ in reheat furnace fuel use. ${ }^{11}$ Reduction of the temperature of the steel leaving the furnace also saves fuel and is possible with changes in rolling technology.

There are many opportunities for improving the reheat furnace itself: automatic controls based in part on sensing the surface temperatures of the slab and separately controlling different zones of the furnace, coke oven gas capability, heat recovery including waste 
heat boilers, improved insulated water-cooled skids or walking-beam technology, and improvements in the envelope (improved refractories, reduced leakage, effective charging doors). Consider one such improvement, the control of the air-to-fuel ratio, as sensed by oxygen concentration in the stack, enabling reduction of excess air to $10 \%$ and less. If, for example, excess air is reduced from 25 to $10 \%$, in typical conditions fuel consumption is reduced by $4 \%{ }^{11}$

Final finishing. Two opportunities among the varied processes for final finishing of steel into products are annealing furnaces and advanced process controls. As with soaking pits and reheat furnaces there are extraordinary opportunities to save energy in annealing furnaces. The radiant-tube furnace is one common type. The steel to be annealed is in a box with a special atmosphere. The flame and combustion gases are contained in tubes outside the box, with heat transfer to the box by radiation. An alternative is direct firing: flame and combustion gases flow around the box. Problems of damage to the box are minimized by design and control measures. ${ }^{17}$ Many radiant-tube furnaces are being converted, at relatively low cost, to direct firing; recuperators are being added; and systematic scheduling to reduce operating hours adopted. Reductions in fuel requirements of $30-40 \%$ are achieved.

Every stage of production in a steel mill is subject to sensing of physical parameters and on the basis of that information, making controlled adjustments. Some of the new developments involve on-line, or real-time, advanced process controls in which adjustments are made in processing the particular material sensed (feedforward controls). Advanced controls encompass: (1) sensing critical physical characteristics of production; (2) rapid analysis of those characteristics and determination of desired actions to modify the process (e.g. downstream from the point of measurement); and (3) automatic implementation of some of these actions. At the same time, information is made conveniently available to operators so they can make an informed judgment on the state of the process and intervene as appropriate.

Electronic computation is just one part of this capability. The critical element is typically the sensors. With computer support more kinds of sensing are becoming effective. The actuators are also important. These devices must be accurate enough and respond rapidly enough to carry out the function.

I will very briefly discuss the use of advanced controls in only one process, cold rolling. In making flat products, for example, thickness as a function of length has long been measured and controlled for by adjusting the position of rolls. New techniques involve optical measurements, and fast control with hydraulic roll positioning and/or distributed cooling. ${ }^{26}$ Shape or flatness (as contrasted with waviness or buckling) and profile (variation in thickness across the strip) can be measured. Research and development is being conducted on optical detection of surface defects. These kinds of automatic controls improve uniformity and reduce rejection of product. Very significant increases in yield have occurred in U.S. practice recently. This yield improvement has substantial energyconservation benefits. Advanced controls are also being installed or being developed for processing hot steel.

An important outgrowth of advanced controls is that through them we can learn in detail about the performance of the production processes at the plant. By this means, all aspects of production can be scientifically examined and improved, or replaced by better processes.

\section{An Energy-Conservation Plan for a Sample Steel Mill}

A major energy conservation plan was developed in 1981-1982 by engineers at a typical medium-sized integrated steel mill which produces sheet products. This mill is probably of average energy efficiency. As at many other U.S. mills there are a few major new facilities, such as a continuous caster, but most facilities are old. The plan would cost up to $\$ 56$ per ton/yr of total capacity to produce mill products $(\$ 62 / \mathrm{t})$. If adopted in its entirety it would reduce the mill's energy consumption by $20 \%$.

The plan focuses on the blast-furnace complex and reheat furnaces. A large part of the 
energy savings comes from improved heat recovery and more complete utilization of byproduct fuels (coke-oven and blast-furnace gases). Almost none of the projects in the plan have savings other than energy conservation. (In part this is associated with bureaucratic practice at this firm. For example modernization of basic oxygen vessels is not categorized as energy conservation, although it has energy benefits.) Improved controls are involved in projects at reheat furnaces and soaking pits. Such a plan developed today would put additional emphasis on advanced automatic controls.

The potential economic performance of the plan, with seven projects or groups of projects shown explicitly, is presented in Fig. 8. For most of the projects natural gas is the

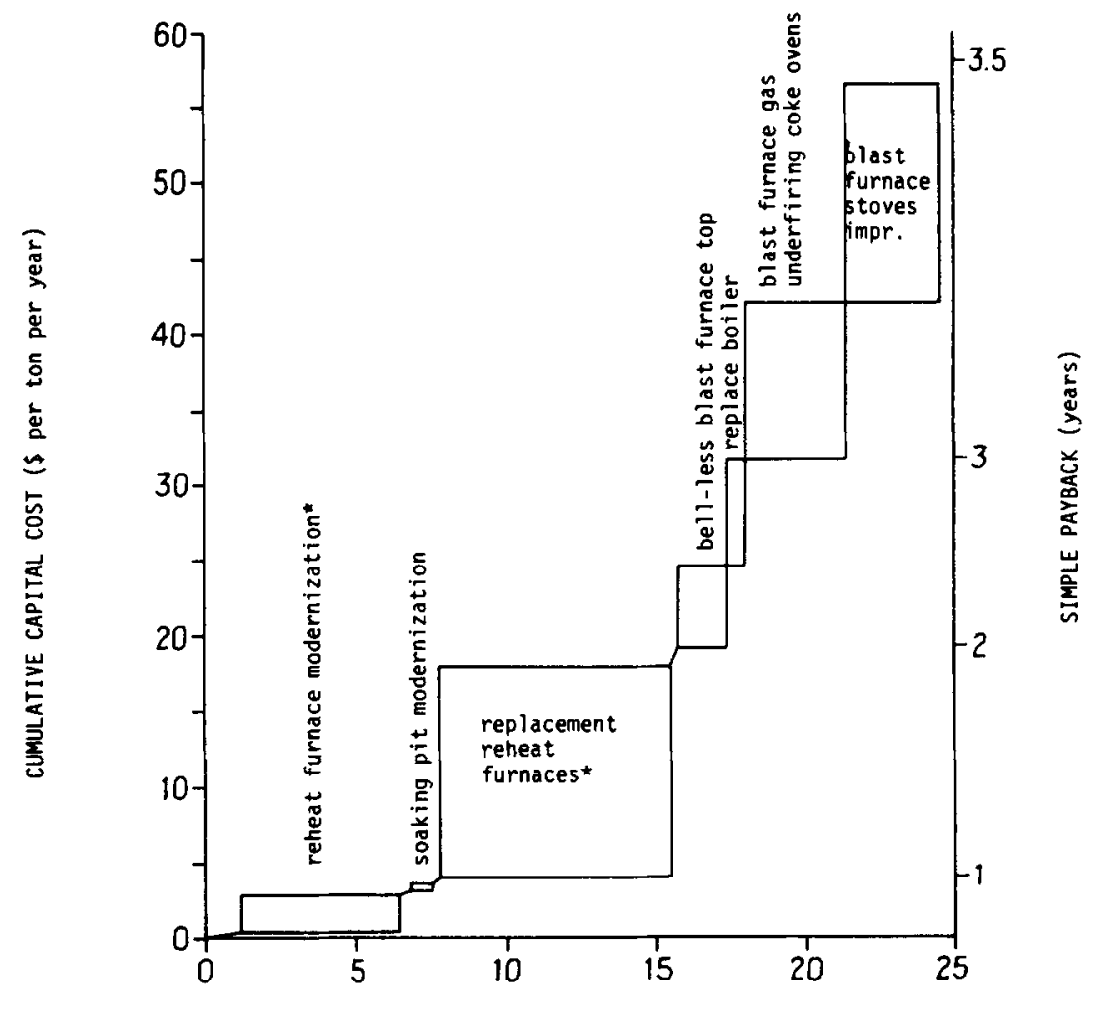

CUMULATIVE ENERGY SAVINGS (percent)

*These projects substantially overlap each other. Net total energy savings for the plan are $20 \%$.

Fig. 8. Sample steel mill energy conservation plan. Capital cost, energy savings and economic performance.

fuel ultimately saved; the assumed price of gas is $\$ 4.00 / \bar{M} B t u\left(\$ 140 / \mathrm{km}^{3}\right)$. The projects have been placed in the figure in order of their simple payback, the ratio of the capital cost to the benefits from the first year of full operation. Sample payback values are indicated on the figure. (The major projects shown, excluding the reheat furnace modernization, have economic lives of $10-20 \mathrm{yr}$; they have the same ordering if compared using an aftertax discounted cash flow analysis such as internal rate of return.) The least favored project, the group of blast-furnace stove improvements, has an internal rate of return of $26 \%{ }^{28}$

As is typical at U.S. firms, in economic analysis of projects like these it was assumed that production would be at design or preferred capacity levels. Some equipment conserves energy at the design rate regardless of production level, but much doesn't, and for the latter savings are likely to be less than calculated. This overoptimism would not substantially change the overall picture suggested by Fig. 8. One way of coping with this uncertainty, where there are multiple facilities such as blast furnaces or reheat furnaces, is to modernize part of the capacity. 
Carrying out all the projects shown in Fig. 8 would reduce the cost of producing steel at this mill by about $\$ 12 /$ ton of mill products. The calculation of this cost reduction takes into account the capital cost of the projects (the payments the firm would make to creditors and shareholders). This cost reduction is significant when compared to the total cost of operating the mill. For comparison, the value added by basic steel mills averaged $\$ 265 /$ ton of mill product in $1980,{ }^{29}$ and energy cost (including metallurgical coal) about $\$ 85 /$ ton. In terms of 1981 prices, this cost reduction would be about $2.5 \%$ of the value of shipments.

\section{Expectations for the Year 2000}

There are many uncertainties about the energy intensity of the steel industry in the U.S. during the next two decades. Much of the energy use is roughly production independent; e.g. many furnaces are operated full-on even when production is slow, so future energy intensities are sensitive to the uncertainty about capacity utilization. In addition the materials flows and levels of use of some major processes are particularly uncertain because the structure of the industry is changing. ${ }^{5}$ There are two developments that may rapidly grow in importance since relatively little capital expenditure would be required: recycling and importation of rough shapes such as slabs. Rapid growth of either would substantially decrease energy use per ton of mill products.

The continued closure of inefficient facilities and mills and gradual modernization of remaining mills will also reduce the energy intensity. Two years ago I analyzed the potential for these latter changes in energy intensity during the 1980s, based, in part, on data on energy conservation expenditures by the industry and on the cost of saving energy (data like that shown in Fig. 8). ${ }^{3}$ I concluded that the energy intensity would drop on average almost $2 \% / \mathrm{yr}$ over the $1980 \mathrm{~s}$ in roughly comparable amounts due to further operational improvements, new major facilities within existing mills, and smaller modernization and energy-conservation investments. If one doesn't consider the great uncertainties mentioned in the two paragraphs above, I think this prediction holds good. However, very rapid progress in reducing the energy intensity was made in the last two or three years. The rate of improvement may be slower in the late 80 s and a slower rate would very likely characterize the 90 s.

In this prognosis I have not yet mentioned radical technical change except change that might expand the uses of post-consumer scrap. It could be very beneficial to U.S. producers if radical developments in thin casting and in the front end of the process were rapid and successful. If such technologies cut production costs enough, they could enable the industry in the U.S. to again dominate domestic markets, even though foreign producers also adopted them. In addition, major energy intensity reductions would be achieved in shaping and treating, and iron ore reduction might be achieved using ordinary coal.

\section{REFERENCES}

1. Energy Information Administration, Monthly Energy Review, U.S. Department of Energy, Washington, D.C.

2. Energy and Environmental Analysis, Inc., "The Industrial Sector, Energy Consumption Data Base for 1975 and 1976", a report to the Energy Information Administration, USDOE (1980); Solar Energy Research Institute, A New Prosperity: Building a Sustainable Energy Future, pp. 385 ff., Brick House, Andover, Mass. (1981).

3. M. Ross, Natural Resources J. 24, 369 (1984).

4. Committee on Interstate and Foreign Commerce, U.S. House of Representatives, "The Energy Factbook", Committee Print 98-IFC-60 (1980); see also Ref. 1.

5. M. Ross, E. D. Larson and R. H. Williams, Energy 12 (10/11), 953 (1987).

6. E. P. Gyftopoulos, L. J. Lazarides and T. F. Widmer, "Potential Fuel Effectiveness in Industry", report to the Energy Policy Project of the Ford Foundation, Ballinger (1974); E. H. Hall et al., "Evaluation of the Theoretical Potential by Energy Conservation in Seven Basic Industries", report by Battelle Columbus Laboratories to the Federal Energy Administration (1975).

7. Reports to U.S. Department of Energy on Energy Efficient Improvement and Recovered Material Utilization, issued by American Paper Institute, New York, N.Y., and American Petroleum Institute, Chemical Manufacturers Association, American Iron and Steel Institute and Aluminum Association, Washington, D.C (June 1984).

8. American Iron \& Steel Institute, A. Statist. Rep. (1983); and earlier issues.

9. R. W. Bouman, Iron and Steelmaker 23 (January 1983) 
10. Battelle Columbus Laboratories, "Potential for Energy Conservation in the Steel Industry", Appendix A, a report to the Federal Energy Administration (1975); F. T. Sparrow, "Energy and Materials Flows in the Iron \& Steel Industry", Energy and Environmental Systems Division, Argonne National Laboratory (1982).

11. International Iron \& Steel Institute, Energy and the Steel Industry (1982).

12. "Steel at the Crossroads: The American Steel Industry in the 1980s", American Iron \& Steel Institute (1980); D. F. Barnett and L. Schorsch, Steel: Upheaval in a Basic Industry, Ballinger, Cambridge, Mass. (1983).

13. John Elliott, "The Future of Metallurgy", a talk at the ASEA Centenial, Massachusetts Institute of Technology (1983); J. D. Desai, "Technology Development of Thin Strip Metal Casting-Feasibility Study", report to the Office of Industrial Programs, U.S. Department of Energy, by General Electric Co. (January 1984).

14. S. Eketorp, Energy 12 (10/11), 1153 (1987).

15. T. Johannson, P. Steen, E. Bogren and R. Fredrickson, Science 219, 355 (1983); G. Hane, et al., "A Preliminary Overview of Innovative Industrial Materials Processes", report PNL-4505 to the U.S. Department of Energy, by Pacific Northwest Laboratory (1983).

16. C. C. Schueppert, Br. Steelmaker 48, 10-13 (June 1982); H. Straube, Acta tech. belg. 23(3), 5.1-5.29 (1983); D. Coutsouradis et al. Acta tech. bely. 23(3), 7.1-7.24 (1983); I. Le May and L. McDonald Schetky, Copper in Iron and Steel, Wiley-Interscience, New York (1982); J. A. Vollomy, Ind. Heating 34-38 (June 1985).

17. "Energy Conservation in the Steel Industry", American Iron \& Steel Institute (1976).

18. A. D. Little, Inc., "Research, Development and Demonstration for Energy Conservation: Preliminary Identification of Opportunities in Iron \& SteeImaking", report SAN/1692-1 to the U.S. Department of Energy (1978); J. R. Sexton, Iron Steel Engr 38 (January 1983).

19. E. J. McCluskey, Iron Steel Engr 25 (July 1983).

20. G. McManus, Chilton's Iron Age 21 (5 November 1984); "Mixed Gas Blowing", 4th Process Technology Conference, Iron and Steel Society of AIME (April 1984)

21. G. McManus, Chilton's Iron Age MP-7 (3 January 1983).

22. J. Isenberg-O'Loughlin, 33 Metal Producing 45 (November 1982).

23. E. P. Gyftopoulos and W. J. DiBartola, Energy 12 (10/11), 1183 (1987).

24. J. O. Hersley and J. A. Boggs, Iron Steel Engr 35 (August 1983).

25. F. Hollander, Iron Steel Engr 55 (June 1983); L. J. Grafe, Iron Steel Engr 43 (January 1985).

26. J. Dwyer Jr, 33 Metal Producing 37 (July 1984); G. McManns and P. Aiman, Chilton's Iron Age 39 (1 March 1985).

27. Survey of Current Business, U.S. Department of Commerce, various issues.

28. Assuming a 15 -year economic life, a $6 \%$ inflation rate for all costs and benefits, a $50 \%$ tax rate, depreciation as in the 1981 tax code and an investment tax credit of $10 \%$.

29. Annual Survey of Manufacturers, U.S. Bureau of the Census, various issues. 